Ensino, Saúde e Ambiente - V9 (3), pp. 346-372, Dez. 2016

\title{
O IMPACTO DO CURSO DE SUPORTE BÁSICO DE VIDA A DISTÂNCIA VIA WEB NA MARINHA DO BRASIL
}

\section{THE IMPACT OF THE BASIC DISTANCE LIFE SUPPORT COURSE VIA WEB IN THE BRAZILIAN NAVY}

\author{
Raul Luiz de Souza Cavalcanti ${ }^{1}$ Carlos Alberto Andrade Monerat ${ }^{2}$ Leonardo dos Santos \\ Barcelos $^{3}$ Raphael Pessoa de Oliveira ${ }^{4}$ Thayene Leite da Silva ${ }^{5}$ \\ ${ }^{1}$ Centro Universitário Celso Lisboa/Docente Curso de Enfermagem/Mestre em Ensino de Ciências da \\ Saúde e Meio Ambiente/Oficial Militar da Reserva da Marinha do Brasil/prof.raul.cavalcanti@gmail.com \\ ${ }^{2}$ Centro Universitário Celso Lisboa/ Docente Ciclo Básico em Saúde/ Mestre em Ensino de \\ Ciências/Doutorando em Ensino de Ciências/carlos.monerat@gmail.com \\ ${ }^{3}$ Centro Universitário Celso Lisboa/Discente Curso de Enfermagem/Técnico em Segurança do \\ Trabalho/leonardo.s.barcelos@gmail.com \\ ${ }^{4}$ Centro Universitário Celso Lisboa/Discente Curso de Enfermagem/Tecnólogo em Emergência e \\ Primeiros Socorros/raphaelpessoa@yahoo.com.br \\ ${ }^{5}$ Centro Universitário Celso Lisboa/Discente Curso de Enfermagem/thayene 1@ hotmail.com
}

\section{RESUMO}

O objetivo dessa pesquisa foi investigar no discurso dos alunos, enfermeiros militares, o impacto do curso de Suporte Básico de Vida à Distância para Praças, na Marinha do Brasil, como o resultado da realização desse curso tem influenciado na prática profissional. Trata-se de estudo de caso, com abordagem qualitativa, realizado por meio da utilização de instrumentos de coleta de dados que foram utilizados para constituir informações sobre os sujeitos e o cenário da pesquisa. Os sujeitos da pesquisa foram cinco Sargentos Enfermeiros, Técnicos em Enfermagem, do sexo masculino, com média de dez anos de serviço ativo na Marinha do Brasil, egressos do Curso de Suporte Básico de Vida à Distância da Escola de Saúde do Hospital Naval Marcílio Dias, que foram escolhidos aleatoriamente. Foram aplicadas entrevistas semiestruturadas a estes sujeitos, com a finalidade de ampliar o discurso dos mesmos acerca da fase à distância. Nesta etapa, utilizamos a análise do discurso no qual, de acordo com Maingueneau (2008), isto é, a Análise do Discurso Francesa, que expõe que "discurso" é uma dispersão de textos (ou falas) transcritos cujo modo de inscrição histórica será definido como um espaço de regularidades enunciativas. Ou seja, tem uma dupla voz no discurso, heterogeneidade do discurso, que se constitui a partir dessas regularidades produzidas histórica, política e socialmente.

Palavras-chave: Ensino à Distância, Internet na Educação, Educação.

\section{ABSTRACT}

The objective of this research was to investigate in the students' discourse, military nurses, the impact of the Basic Distance Life Support for Squares course in the Brazilian Navy, as the result of this course has influenced professional practice. It is a case study with a qualitative approach, carried out through the use of data collection instruments that were used to constitute information about the subjects and the research scenario. The subjects of the research were five Nursing Sergeants, Nursing Technicians, male, with an average of ten years of active service in the Brazilian Navy, 
graduates of the Basic Life Support Course at a Distance from the School of Health of Naval Hospital Marcílio Dias, which were chosen randomly. Semi-structured interviews were applied to these subjects, in order to broaden their discourse about the distance phase. In this stage, we use discourse analysis in which, according to Maingueneau (2008), that is, the French Discourse Analysis, which exposes that "discourse" is a dispersion of transcribed texts (or speeches) whose historical mode of inscription will be Defined as a space of enunciative regularities. That is, it has a double voice in the discourse, heterogeneity of discourse, which is constituted from these regularities produced historically, politically and socially.

Keywords: Distance Learning, Internet in Education, Education.

\title{
INTRODUÇÃO
}

O Ensino à Distância $(\mathrm{EaD})$ via web surgiu como uma importante possibilidade de formação educacional para as populações, mesmo aquelas distantes dos centros urbanos que concentram o maior quantitativo de escolas dos mais diversos níveis.

\begin{abstract}
A tecnologia permite a experiência em primeira pessoa, experiências vivenciais e não apenas virtuais. $O$ aprendizado deve sustentar-se na curiosidade do aluno, em sua procura pelo conhecimento. Uma realidade virtual de eventos incapazes de enriquecer as sensações, segundo o modelo mental de um técnico que prepara uma aula de acordo com um procedimento frio e calculado, resultará sempre numa aula sem sabor.

O que é melhor? Visitar virtualmente algum site ou interagir com avatares e agentes em uma aventura emocionante e divertida? É preciso lembrar sempre que o computador e os meios de comunicação podem até substituir o professor profissional, mas jamais o educador apaixonado por sua arte. (TORRES; FIALHO, 2008, p. 457).
\end{abstract}

De acordo com Nunes (2008), para o sucesso pedagógico, é necessário que tenhamos cuidado, isto porque atualmente, um curso à distância não é mais um curso por correspondência unidirecional, em que se enviam livros e textos pelo correio e se espera que o aluno já saiba estudar e aprender. É preciso cercar-se de uma multiplicidade de recursos para alcançar êxito.

Em dias atuais, a modalidade de $\mathrm{EaD}$ que tem despertado grande interesse é a que ocorre pela rede mundial de computadores - a Internet. ${ }^{1}$ Dessa maneira, a partir das ferramentas disponibilizadas pela Plataforma no Ambiente Virtual de

\footnotetext{
${ }^{1}$ Internet - É qualquer conjunto de redes de computadores ligadas entre si por roteadores e gateways como, p. ex., aquela de âmbito mundial, descentralizada e de acesso público, cujos principais serviços oferecidos são o correio eletrônico (q. v.), o chat (q. v.) e a Web (q. v.) Cf. Dicionário Aurélio Eletrônico. $W e b$ - Recurso ou serviço oferecido na Internet (rede mundial de computadores), e que consiste num sistema distribuído (q. v.) de acesso a informações, as quais são apresentadas na forma de hipertexto, com elos entre documentos e outros objetos (menus, índices), localizados em pontos diversos da rede. $C f$. Dicionário Aurélio Eletrônico.
} 
Aprendizagem (AVA), o aluno poderá interagir em tempo real com outros alunos e professores, estreitando ainda mais essas relações na construção do conhecimento.

Entretanto, os cursos poderão ser apresentados de diversos modos e realizados totalmente à distância, quando não há encontro direto do professor com o aluno, ou semipresencial, com estrutura híbrida, no qual são obrigatórios encontros presenciais para testes de conhecimento ou facilitação no desenvolvimento de competências de cunho prático.

A relevância para a realização de cursos em saúde à distância na Marinha do Brasil, é a necessidade de atualização e aprimoramento dos profissionais das diversas Organizações Militares (OM), em especial daqueles que se encontram em constante embarque marítimo resultante de exercícios e missões militares.

Nesse sentido, o Curso de Suporte Básico de Vida à Distância para Praças, oferecido pela Divisão de Ensino à Distância da Escola de Saúde do Hospital Naval Marcílio Dias (HNMD), parece ser uma alternativa para solucionar esse problema.

O objetivo deste artigo é apresentar, no discurso dos alunos enfermeiros militares de nível médio, como o resultado da realização desse curso tem influenciando na prática profissional.

\section{O Ensino a Distância (EaD)}

Até antes do século $\mathrm{XV}$, os escritos eram realizados manualmente, o que dificultava a transmissão do conhecimento entre os povos (ALVES, 1998). A partir da invenção da imprensa por Guttemberg, na Alemanha, em 1442, um maior número de pessoas passou a ter acesso às informações, ainda que este acesso fosse limitado às classes de maior poder econômico. Posteriormente, Morse (em 1820) e Graham Bell (em 1876) contribuíram tecnologicamente com suas criações, respectivamente, o telégrafo elétrico e o telefone, estreitando a comunicação entre os povos e favorecendo o início do processo das telecomunicações.

Identificamos, em processos educativos passados, o Ensino à Distância fazendo parte da formação de pessoas com interesse em aprender, como relatado abaixo:

$\mathrm{O}$ EaD teve diferentes estágios ou gerações:

- $1^{\text {a }}$ Geração: textual - de 1876 a 1970 - estudo por correspondência, cujo meio de comunicação era o material impresso, geralmente guia de estudos com exercícios escritos e outras tarefas enviadas pelo correio. Muitos dos cursos a distância espalhados pelo mundo ainda são conduzidos por correspondência; 
- 2a Geração: analógica - de 1970 a 1990 - além do material impresso, são utilizadas transmissões por televisão aberta, rádio, fitas de áudio e vídeo, com interação por telefone,satélite e TV a cabo; e

- $3^{a}$ Geração: digital - a partir da década de 1990 - baseada em redes de computadores, recursos para conferência e multimídia. (DEnsM-5001, 2005, p. $1-1^{2}$ )

Segundo Peters (2001), as gerações não são suplantadas; elas são inteiradas, agindo em conjunto ou em separado. O que percebemos atualmente é que há uma integralização de tecnologias que foram desenvolvidas e se integraram, compartilhando os estágios decorrentes ao longo do tempo. As possibilidades são inúmeras quando temos a necessidade de estimular o aluno nessa possibilidade educativa, como afirma Nunes (2008, p. 3):

Do início do século XX até a Segunda Guerra Mundial, várias experiências foram adotadas, sendo possível melhor desenvolvimento das metodologias aplicadas ao ensino por correspondência. Depois, as metodologias foram fortemente influenciadas pela introdução de novos meios de comunicação de massa.

Numa linha do tempo, por meio de pesquisas, encontramos dados que afirmam que desde 1728 tem-se notícia de Ensino à Distância nos Estados Unidos; desde 1840 na Grã-Bretanha; na Suécia, desde 1883; no Canadá, desde 1889; na Austrália, desde 1910; na Nova Zelândia, desde 1922; no Japão e na Rússia, desde 1930; na China e na Indonésia, desde 1950, sendo a África a pioneira no ensino superior nessa modalidade de transmissão de conhecimentos:

A Universidade of South Africa é a mais antiga das universidades a distância.
Antes de 1970, ela era a única universidade a distância autônoma no mundo
inteiro. Ela remonta a uma University of the Cape of Good Hope, fundada em
1873, que inicialmente - como outrora a University of London - apenas
realizava exames. Só em 1946 ela começou paulatinamente, também, a
ensinar, e nos anos 50 e 60 realizou como primeira universidade à distância
um trabalho pioneiro. Estamos, portanto, aqui diante de uma universidade à
distância de longa tradição, que tem suas raízes ainda no século XIX.
(PETERS, 2001, p. 280 apud DEnsM 5001, 2005)

Segundo Nunes (2008, p.15.), em 1928, a British Broadcasting Corporation (BBC), de Londres, iniciou a promoção de cursos utilizando o rádio para educação de adultos. Essa tecnologia de comunicação foi usada em vários países com os mesmos propósitos, até mesmo no Brasil, desde a década de 30.

\footnotetext{
${ }^{2}$ Manual para elaboração de cursos à distância, da Diretoria de Ensino da Marinha (DEnsM-5001, 2005, p. 86), OSTENSIVO - Marinha do Brasil.
} 
$\mathrm{Na}$ década de 70, a América Latina foi fortemente influenciada pela Universidade Aberta da Venezuela e pela Universidade Estadual da Costa Rica.

Em 1982, a Grã-Bretanha criou a Open University com uma proposta diferenciada de ensino que, por meio da utilização de impressos e de televisão, em cursos intensivos nos períodos de recesso de universidades convencionais, realizou cursos de boa qualidade acadêmica para seus alunos, que competiam igualmente em mercado de trabalho com os egressos de universidades convencionais. Nunes (2008, p.6) afirma que esta universidade "nasceu no momento em que se acreditava na capacidade da televisão em promover as mudanças educacionais desejadas para a incorporação de grandes contingentes populacionais nos sistemas de ensino". 3

O Ensino à Distância possui características importantes: é necessário que haja distância entre professor e aluno; que sejam disponibilizados recursos para que ocorra interação entre ambos; diante das novas Tecnologias de Informação e Comunicação (TIC) ${ }^{4}$, esses espaços devem ser estreitados de acordo com o objetivo do curso, pois o aluno precisa ser acompanhado pelo professor; as interações são necessárias. Assim sendo, mesmo com a possibilidade de o aluno poder gerenciar o aprendizado pela flexibilidade do tempo, o professor deverá interagir, estimulando e questionando esse aluno, sendo esta uma maneira de acompanhar o seu desenvolvimento.

De acordo com Sancho (2006), é necessário que as TIC tornem-se meios de ensino que melhorem os processos e os resultados pedagógicos, e que se coloquem em prática projetos educativos que atualmente respondam às necessidades formativas dos alunos.

\section{TECNOLOGIAS DA INFORMAÇÃO E COMUNICAÇÃO (TIC) E EDUCAÇÃO} Ciberespaço

Os processos educativos mediados pelo computador tem estimulado o surgimento de tecnologias para a aprendizagem e a criação de ambientes virtuais por meio de plataformas de interação com suas diversas ferramentas, assim facilitando a comunicação entre alunos e professor e entre os próprios alunos, numa rede de

\footnotetext{
${ }^{3}$ Open University - Hoje, mais de 200 mil alunos estudam em casa ou no local de trabalho por intermédio de materiais diversos (impressos, kits, vídeos, fitas de áudio, softwares, jogos e Internet). Há cursos abertos, de extensão ou de conhecimentos gerais, traduzidos para várias línguas e oferecidos por diversos meios. Atualmente, há um pouco mais de 40 mil alunos em cursos de pós-graduação (NUNES, 2008, p.6).

${ }^{4}$ TIC - Tecnologia de Informação e Comunicação.
} 
relacionamentos onde o conhecimento é construído e compartilhado. A propósito, segue-se a explicação de Teles (2008, p. 72):

\begin{abstract}
Na sala de aula virtual, o ambiente é diferente do presencial, pois não existem fisicamente as quatro paredes, o quadro negro, a disposição das cadeiras, geralmente todas voltadas para o professor. Também mudam as noções de espaço geográfico e de tempo: o acesso pode ser feito de qualquer lugar do planeta pela Internet, o tempo é expandido a uma ou mais semanas ou dias, diferentemente da hora regular da sala de aula tradicional.
\end{abstract}

Nesse sentido, de acordo com DEnsM 5001 (2005), a difusão de novos meios de comunicação disponíveis leva à formação de comunidades desterritorializadas (LÉVY, 1998), em que as novas possibilidades em interconexão permitem a criação de comunidades virtuais formadas por afinidades e interesses comuns dos usuários da rede, independente de sua localização geográfica. Para este autor, somos uma aldeia globalizada, uma rede de consumidores de produtos e informações, rede esta formada por pessoas de todo o planeta que se conectam apesar das limitações linguísticas.

Nos processos educativos, a velocidade das informações, as conexões com o mundo e as interações culturais que contribuem com a evolução do saber, vêm possibilitar ao indivíduo compartilhar conhecimento, ensejando o surgimento de novos valores sociais.

Ante o exposto, é possível afirmar que a tecnologia pode transformar o ensino em aprendizagem eficiente no momento em que recursos estejam disponíveis, computadores estejam conectados e professores interessados em despertar os alunos para novas possibilidades visando a construção do conhecimento de maneira interativa.

\title{
A Internet e o Ensino à Distância
}

A utilização da Internet aplicada à Educação favorece inúmeras oportunidades para instituições de ensino, professores e alunos, por ser uma mídia que facilita a motivação destes últimos pela novidade e possibilidades inesgotáveis de pesquisa que oferece. A comunicação torna-se mais rápida, visto que professores e alunos têm ao seu dispor ferramentas como: o correio eletrônico (e-mail) utilizado para a troca de informações, os bancos de publicações e a própria Internet, dando acesso a uma grande variedade de recursos nela disponíveis (figuras, textos, dados, som e vídeo). Nessa mídia, desenvolvem-se "formas novas de comunicação principalmente escrita. Escrevemos de forma mais aberta, hipertextual, conectada, multilinguística, aproximando texto e imagem" (MORAN, 2000, p. 53). 
A web é um banco de dados, ou servidor de aplicações, que contém informações passíveis de serem manipuladas por software de navegação (browser), sendo um dos serviços mais utilizados da Internet. Um servidor web pode incluir texto, som, imagem estática e vídeo. Cada site web é constituído por um conjunto de páginas sobre um determinado assunto, que pode ser interconectado com outros sites. Nas páginas existentes na web é possível, a partir de palavras, frases, figuras ou ícones, fazer um link de modo a funcionar como "endereço" de outras páginas, num sistema hipertextual, permitindo o deslocamento entre páginas com o simples uso do mouse.

A difusão da Internet na sociedade tem produzido impactos em diferentes setores, entre eles o educacional. Isso acarreta a crescente demanda por sistemas que dêem suporte a formas de educação on-line que se utilizam de AVA (Ambientes Virtuais de Aprendizagem).

Assim, a aprendizagem baseada na Internet deve aproveitar a melhor possibilidade na rede de computadores - comunicação e cooperação entre pares.

O uso do computador na educação traz modificações nas formas de ensinar e aprender; no entanto, sua utilização na transmissão de informações não substitui ou torna desnecessária a presença do professor; ao contrário, permite a identificação de outras funções a serem exercidas por ele, atuando como um facilitador da aprendizagem. As previsões sobre a substituição da escola e dos professores com o surgimento de cursos transmitidos por rádio, televisão e, mais recentemente, pelo computador, não têm sido sustentadas.

\section{A MARINHA DO BRASIL E A ESCOLA DE SAÚdE DO HOSPITAL NAVAL MARCÍLIO DIAS}

A área de saúde militar trata de problemas associados às atividades de combate e daquelas voltadas para o estudo das conseqüências de operações prolongadas em meio ambiente submarino e aéreo, bem como em regiões de climas adversos, com a Antártica e a Amazônia, além das resultantes do uso de armas nucleares táticas e operações conjuntas com outras Forças ou Nações, tanto em treinamento quanto em situações reais.

Consciente de que seu desempenho depende fundamentalmente do nível de preparo de seus profissionais, a Marinha do Brasil estrutura a carreira de seus militares, Oficiais e Praças sobre os pilares do ensino. Apesar dos incentivos educativos serem direcionados para as ciências exatas, as ciências da saúde e suas subdivisões também 
são contemplados com investimentos com vistas ao aprimoramento da tropa, a fim de suprir as necessidades decorrentes das missões de guerra.

A bordo dos Navios de Assistência Hospitalar, profissionais prestam assistência médica às populações carentes das grandes bacias hidrográficas do país, participam das operações de busca e salvamento, embarcam em navios e aeronaves, prestando socorro às vítimas de sinistros de toda sorte; apoiando as tropas de Fuzileiros Navais nos desembarques. Com isso, propiciam a cada soldado a certeza da confiança na existência de uma estrutura que zela por sua sobrevivência, e embarcados nos navios da Esquadra, garantem a manutenção da capacidade de combate de nossos homens no mar.

A Marinha, por intermédio da Escola de Saúde do Hospital Naval Marcílio Dias (HNMD), justifica sua existência com a função de formar profissionais de saúde, militares e civis, com qualificação e especialidades adequadas no atendimento às populações.

A Escola de Saúde é uma escola de enfermagem militar onde todo processo educativo é desenvolvido pelo Sistema de Ensino Naval (SEN), sob supervisão da Diretoria de Ensino da Marinha (DEnsM), numa organização bem estruturada e consciente da responsabilidade de garantir a qualidade da formação pessoal da Marinha do Brasil.

A Escola de Saúde do HNMD tem como missão investir na qualificação do homem, visando a formação técnica de profissionais voltada para a prevenção, manutenção e recuperação do bem estar físico e psíquico do militar e sua família. A respeito da Escola de Saúde em questão, o acervo histórico da Marinha registra o seguinte:

A primeira Escola de Enfermagem, criada em 1916 e funcionando nas dependências do Hospital Central da Marinha, destinava-se exclusivamente a militares e tinha como objetivo a preparação do pessoal embarcado em navios e unidades de terra. A Escola de Auxiliares de Enfermagem para civis do sexo feminino foi criada em 1949, na antiga Associação Médica de Saúde da Armada (AMSA). Em 1975, ambos os cursos passaram à subordinação do CMNRJ. A Escola de Saúde só veio a ser criada em 1979, através do Decreto número 8316 de 12/02/1979 e integrada ao Sistema de ensino Naval pela Lei número 5450/79.

A Escola de Saúde tem hoje 28 anos de existência e é constituída pelas Divisões: Ensino Superior, Ensino Médio, Orientação Pedagógica e Educacional, Ensino Complementar e Apoio ao Ensino, Ensino a Distância e Legislação.

Possui atualmente um corpo discente de aproximadamente 400 alunos, distribuídos nos seguintes cursos e estágios: Aperfeiçoamento para Oficiais Médicos, Dentistas, Farmacêuticos e Enfermeiros, Residência Médica e em Enfermagem, Pós-Graduação strictu e lato sensu no país e no exterior, Medicina de Aviação, Medicina de Mergulho, Aperfeiçoamento e Especialização para Praças na área de Enfermagem: Patologia Clínica, 
Banco de Sangue, Gasoterapia, Radiodiagnóstico, Medicina Nuclear, Medicina Hiperbárica, Prótese Odontológica, Radioterapia, entre outros. (MARINHA DO BRASIL, 2004, p.10)

Não sendo uma Organização Militar (OM) independente, pois está integrada ao HNMD, a Escola possui estrutura própria onde estão distribuídas as áreas administrativas e de ensino, com salas de aula, salas para o desenvolvimento de técnicas para assistência à saúde, laboratório de informática e pátio externo onde são realizadas as solenidades de formaturas e os exercícios práticos com simulações de situações de trauma para atendimento pré- hospitalar.

Embora vinculada ao Sistema de Ensino Naval (SEN), a Escola de Saúde busca equiparar sua formação à legislação educacional civil, uma vez que foi por intermédio do Parecer no 290/85, da Secretaria Estadual de Educação do Rio de Janeiro, que recebeu seu credenciamento, bem como a autorização de funcionamento.

\section{O Suporte Básico de Vida (SBV)}

De acordo com Batigália (2002) apud Diniz e Silva (2015, p.150), a Organização Mundial de Saúde (OMS), determinou que o termo "acidente" é definido "como um acontecimento independente da vontade do ser humano. Esse acontecimento é provocado por algum de tipo de força exterior e que atue rapidamente sobre o indivíduo, com consequências físicas ou mentais. ”

Para o Prehospital Trauma Life Support (PHTLS, 2007, p. 5), [...] acidente é "um evento ocorrido por acaso ou oriundo de causas desconhecidas" ou "um acontecimento desastroso por falta de cuidado, atenção ou ignorância".

Incidente é o evento não planejado que tem o potencial de levar a um acidente.

Os primeiros socorros são procedimentos básicos de emergência que devem ser aplicados a uma pessoa em situação de risco de vida, procurando manter os sinais vitais bem como impedir o agravamento até que a vítima adequada assistência. (FONSECA, 2008).

Sendo assim, o indivíduo que primeiro inicia o auxílio, geralmente é aquele que presenciou ou chegou imediatamente após o ocorrido, necessita manter a calma para agir sem pânico, procedendo de forma rápida, precisa e com precaução, atento as condições que não coloquem em risco a vítima. (FONSECA, 2008)

O Suporte Básico de Vida (SBV) apresenta protocolos simples, onde todo indivíduo tem autonomia para salvar pessoas. Para Rocha (2011, p.10), 
[...] o SBV caracteriza-se pela realização de manobras não invasivas, ou seja, não se aplica procedimentos de suporte ventilatório e circulatório como, por exemplo, acesso venoso ou intubação orotraqueal. No SAV, por sua vez, esses procedimentos invasivos são realizados, fazendo-se presente uma equipe de médico ou enfermeiro.

O manejo do SBV obedecendo etapas a serem cumpridas, deve ser realizado imediatamente no local do sinistro, como primeira intervenção, em indivíduos com risco de vida. Esses procedimentos poderão ser realizados por leigos ou profissionais devidamente capacitados, em busca de diminuir co-morbidades em população vítima de mal súbito, parada cardiorrespiratória ou obstrução das vias aéreas por corpo estranho. (PERGOLE e ARAÚJO, 2008).

Por ser um protocolo de fácil aprendizagem e execução, o SBV necessita de divulgação, pois quanto maior número de pessoas preparadas para ajudar as outras, haverá melhora nas estatísticas e uma redução significativa nas taxas de mortalidade.

Em âmbito militar, os riscos decorrentes dos exercícios de situação de guerra em virtude de treinamentos, viagens de adestramento em navios e Missões de Paz em países aliados, por vezes surgem situações que exigem atendimentos emergenciais para as quais os profissionais de saúde militares necessitam ter conhecimento dos protocolos necessários ao Suporte Básico de Vida, como atendimento pré-hospitalar, que envolve desde a segurança da cena, ou seja, a preservação do local da ocorrência, até a maneira correta da imobilização e transporte da vítima a uma unidade de Suporte Avançado.

Para adquirir esses conhecimentos, é necessário estudo, prática e repetição já que, quando ele assumir a responsabilidade pela vida do paciente, não poderá consultar manuais, e sim, tomar a decisão crítica imediata baseada em conhecimentos e avaliação da situação que se lhe apresentar.

Com intenção em prover assistência adequada, faz-se necessário pessoas com conhecimento sobre a execução de procedimentos, de acordo com protocolos que norteiam as condutas do atendimento, com o objetivo de minimizar maiores agravos. Dessa forma, o Suporte Básico à Vida (SBV) corresponde a uma sequência de ações e procedimentos que podem ser utilizados por quaisquer indivíduos devidamente capacitados, onde são executadas intervenções táticas como primeiro atendimento a ser utilizado em vítimas com risco de vida, sendo realizado em vias públicas ou em domicílio.

O SBV constitui-se do primeiro contato com a vítima buscando a manutenção da vida sem manobras invasivas, que pode ser realizada por leigos e pessoas treinadas em 
primeiros socorros por intermédio da desobstrução das vias aéreas, ventilação e circulação e de imediato a solicitação do serviço móvel de emergência, onde profissionais de saúde realizarão atendimento avançado.

De acordo com a International Council of Nursing (2002) apud Castro (2013, p.16)

[...] No sistema de saúde, estima-se que cerca de 60 a $80 \%$ das situações prejudiciais ao paciente envolvem erros humanos. No entanto, afirmar que o acidente aconteça em decorrência dele conduz à culpabilidade e à humilhação das pessoas. Uma análise adequada do profissional de saúde e culpá-lo não eliminam os fatores de risco subjacentes.

Com o propósito de obter uma regulação de conduta e atualização de conhecimentos, foi criado o curso de Suporte Básico de Vida (SBV) a distância para militares da Marinha do Brasil.

\section{A ENFERMAGEM MILITAR}

A Enfermagem Militar possui particularidades que diferem do meio civil. Sendo assim, é preciso estar apto a atender situações que envolvam cenários diversos em terra, mar ou ar. As situações limítrofes que podem surgir, obrigam ao desempenho de ações que exigem bom preparo físico e emocional, além de conhecimentos específicos da vida militar e profissional, para atuar nos diversos espaços do País.

De acordo com Alcântara (2005, p.34), "cenário é o local onde ocorre a cena", ou seja, onde ocorre algum acontecimento. No nosso estudo, cenário é o espaço de batalha onde atuam os combatentes.

Durante os exercícios e simulações de estado de guerra, os militares são treinados para atuar nas diversas áreas para as quais foram capacitados. Os instrutores militares fazem parte desse processo, facilitando o desenvolvimento de competências técnicas importantes para que o Enfermeiro de nível médio possa desempenhar com segurança e conhecimento suas atividades.

\footnotetext{
Ao ser identificada uma situação de risco pelo enfermeiro militar ele deverá imediatamente procurar neutralizá-la ou removê-la, não permitindo jamais que a próxima vítima seja ele mesmo. Sua vida ali naquele cenário é de um valor incomensurável. Todos, inclusive ele, dependem dele. (ALCANTARA, 2005, p.35)
}

As ocorrências que se apresentarão no decorrer das missões deverão ser sistematizadas por padronizações estabelecidas em cadeias de evacuação, e normativas de conduta profissional institucional que considerem parâmetros de segurança. 
Do enfermeiro militar exige-se bom preparo físico, habilidades com armamento e segurança orgânica.

\section{O curso de Suporte Básico de Vida a distância}

A criação, na Escola de Saúde do HNMD, de cursos à distância para Praças, surgiu da necessidade de mantê-los atualizados, já que atuam nas diversas Unidades de Assistência Médico-Hospitalar da Marinha do Brasil, como referido. Tem como objetivo suplementar a qualidade técnico-profissional desses militares, habilitando-os para o exercício das funções que exijam conhecimentos em Suporte Básico de Vida.

O curso tem início com a abordagem de conceitos básicos sobre Anatomia e Fisiologia Humanas, cuidados relacionados com a Biossegurança, Manobra de Ressuscitação Cardiopulmonar, Suporte Básico de Vida e o Protocolo START ${ }^{5}$, que se refere ao atendimento com múltiplas vítimas. Os conceitos são apresentados por intermédio de módulos que servirão de apoio aos temas relacionados com o conhecimento e abordagem corretos nas manobras de Suporte Básico de Vida em seu módulo específico.

Trata-se de um curso com carga horária total de 60h, com duração de cinco semanas, dividido em cinco Módulos, divididos por capítulos, que por sua vez são subdivididos em unidades de ensino que contém, ainda, exercícios teóricos, trabalhos individuais e em grupo, além de fóruns de discussão e salas de bate-papo que venham a contribuir para o desenvolvimento do aluno na fase à distância.

O curso é gerenciado e ministrado pela Divisão de Ensino à Distância da Escola de Saúde do HNMD e tem, obrigatoriamente, uma fase presencial de três dias em tempo integral na referida Escola. São utilizados três instrutores para a fase à distância, e um para a fase presencial, considerando-se grupos de seis alunos na atividade prática.

Os instrutores de ambas as fases são Enfermeiros militares, com curso de formação em Suporte Básico e/ou Avançado de Vida com chancela em instituição credenciada internacionalmente para o exercício profissional.

\footnotetext{
${ }^{5}$ PROTOCOLO START - (Simple Triage and Rapid Treatament) - protocolo de triagem para atendimento em acidentes com múltiplas vítimas, que significa Simples Tratamento e Rápido Atendimento. A avaliação se iniciara com o questionamento sobre a capacidade da vítima de se locomover e se encerrará com a definição da prioridade de atendimento. As vítimas são classificadas por cores e são atendidas conforme nível de prioridade. Disponível em: http://www.bombeiros.go.gov.br/arquivos/legislacao/manuais_operacionais/PROTOCOLO_PARA_O_SUPORTE_ BASICO_DE_VIDA_2011.pdf
} 
Os recursos necessários para que o aluno possa acompanhar o curso na fase à distância são: processador Pentium ou similar com memória RAM 64 MB e Navegador (browser): preferencialmente Internet Explorer 5.0 ou superior, e acesso à rede de computadores por Internet ou Intranet. Estes recursos devem ser disponibilizados na $\mathrm{OM}$ do aluno, ou por agendamento, se forem utilizadas as diversas salas de aula virtuais disponibilizadas nas OMs do SEN. Na fase presencial, a instrutoria utiliza projetores multimídia, manequins instrucionais, manequins vivos maquiados como vítimas em cenários que imitam situações de conflito e dificuldades de resgate.

\section{O Ambiente Virtual de Aprendizagem (AVA)}

É no Ambiente Virtual de Aprendizagem que os cursos a distância são postados para interação com os alunos. Poderíamos considera-lo de sala de aula virtual e entender que os AVA possuem duas categorias de sistema de distribuição de EaD: a síncrona e a assíncrona. A síncrona, realizada em tempo real, possui como vantagem a interação simultânea entre o tutor $v s$ alunos $v s$ alunos, podendo ser realizada através de TV interativa, teleconferência, vídeoconferência e chats.

A comunicação assíncrona não requer a participação simultânea dos alunos e tutores, podendo ser realizada pelo correio eletrônico, listas de discussão, apresentação de vídeos e cursos por web, possibilitando ao aluno que essas atividades ocorram no seu próprio ritmo de aprendizagem e conforme sua programação.

Para este curso utilizamos o Ambiente TelEduc, que é um AVA para criação, participação e administração de cursos na web, desenvolvido pelo Núcleo de Informática Aplicada à Educação (NIED) da Universidade de Campinas (UNICAMP) em São Paulo. De acordo com Rocha (2003, p. 376),

\footnotetext{
nos últimos anos, inúmeros ambientes computacionais dirigidos à educação a distância (EAD) foram propostos e desenvolvidos em todo o mundo. Alguns obtiveram mais sucesso e passaram a ser explorados comercialmente, outros são de uso restrito das instituições que os desenvolveram. Esses ambientes objetivam facilitar o oferecimento de cursos pela rede [...] e agregam várias tecnologias de comunicação mediadas por computador (CMC) como o correio eletrônico e os sistemas de conferência por computador, aliados a outros recursos da web.
}

O AVA TelEduc foi elaborado a partir das sugestões relatadas pelos próprios usuários, apresentando uma interface simples, não necessitando que o usuário seja especialista na área de computação para poder utilizá-la. 
Ensino, Saúde e Ambiente - V9 (3), pp. 346-372, Dez. 2016

\section{O CAMINHO METODOLÓGICO}

Tratou-se de estudo de caso, com abordagem qualitativa, realizado por meio da utilização de instrumentos de coleta de dados diversificados: análise de documentos, alguns que foram utilizados para constituir informações sobre os sujeitos e o cenário da pesquisa; e outros para coleta de dados - questionários pedagógicos aplicados na fase à distância. Foram aplicadas entrevistas semiestruturadas a cinco sujeitos da pesquisa, com a finalidade de ampliar o discurso dos mesmos acerca da fase à distância.

De acordo com Martins (2002), o estudo de caso é uma categoria de pesquisa cujo objeto é uma unidade que se analisa profundamente. Pode ser caracterizado como um estudo de uma entidade bem definida, como um programa, uma instituição, um sistema educativo, uma pessoa ou uma unidade social. Visa conhecer o seu "como" e os seus "porquês", evidenciando a sua unidade e identidade própria. É uma investigação que se assume como particularística, debruçando-se sobre uma situação específica, procurando descobrir o que há nela de mais essencial e característico. $\mathrm{Na}$ abordagem qualitativa, Minayo (2007) afirma que se verifica uma relação dinâmica entre o mundo real e o sujeito, isto é, um vínculo indissociável entre o mundo objetivo e a subjetividade do sujeito que não pode ser traduzido em números.

\section{Instrumentos de Coleta de Dados}

Foi utilizado o roteiro de entrevista elaborado pelo pesquisador.

Tendo em vista o objetivo da pesquisa, a construção do curso de Suporte Básico de Vida à Distância e seus efeitos na Marinha do Brasil, foi necessário que a pesquisa de campo se desenvolvesse na Escola de Saúde do HNMD, por ser a única nesta área na Marinha do Brasil. Porém, desde a seleção do tema, a objetividade no trabalho foi buscada para não comprometer a validade do estudo.

Quanto à subjetividade, o constante retorno à teoria serviu de recurso controlador, e mesmo distanciador, necessário à fidedignidade da coleta de dados e análise do mesmos. Somado a isto, conforme Ludke e André (1986), a clarificação dos critérios utilizados para seleção de dados, aplicação dos questionários, além da explicitação de como os fatos pesquisados afetaram a pesquisa e serviram de "protetores" da objetividade.

\section{Sujeitos do Estudo}

Os sujeitos da pesquisa foram cinco Sargentos Enfermeiros, Técnicos em Enfermagem, do sexo masculino, com média de dez anos de serviço ativo na Marinha 
do Brasil, egressos do Curso de Suporte Básico de Vida à Distância da Escola de Saúde do HNMD, escolhidos aleatoriamente pelo pesquisador.

Previamente ao início das entrevistas, todos assinaram o Termo de Consentimento Livre e Esclarecido, (conforme previsto na Resolução 196 do Conselho Nacional de Saúde, vigente à época), sendo informados acerca dos objetivos da pesquisa, de que em qualquer momento poderiam desistir de participar do estudo sem nenhum prejuízo de qualquer tipo, e da garantia de sigilo absoluto acerca do que dissessem nos respectivos depoimentos, mediante utilização de um código alfanumérico $\left(\right.$ Ex.: $\left.\mathrm{S}_{1}, \ldots \mathrm{S}_{5}\right)$.

As entrevistas foram previamente agendadas e gravadas com anuência dos participantes, sendo realizadas na Escola de Saúde do HNMD, no laboratório de informática vinculado à Divisão de Ensino à Distância. Posteriormente foram transcritas pelo pesquisador e apresentadas a cada participante, para assegurar a garantia daquilo que haviam dito.

Ao final da coleta de dados, deu-se início à análise dos mesmos, retomando o aprofundamento teórico para um melhor esclarecimento dos fatos.

\section{Análise dos Dados Coletados}

Nesta etapa, utilizamos a análise do discurso. De acordo com Maingueneau (2008), a Análise do Discurso Francesa expõe que "discurso" é uma dispersão de textos (ou as falas) transcritos, cujo modo de inscrição histórica será definido como um espaço de regularidades enunciativas. Ou seja, tem uma dupla voz no discurso, heterogeneidade do discurso, que se constitui a partir dessas regularidades produzidas histórica, política e socialmente.

Para Oliveira (2003, p. 120),

A análise do discurso é a estratégia de pensamento recorrida, visando a que o discurso dos atores institucionais não seja tratado de maneira "conteudista", ou seja, como se existisse nele mesmo ou se tivesse uma causa objetiva exterior.

A respeito deste aspecto, podemos também considerar a análise de discurso como:

Um conjunto de regras anônimas, históricas, sempre determinadas no tempo e no espaço, que definiram em dada época, e para uma área social, econômica, geográfica ou lingüística dada, as condições de exercício da função enunciativa. (FOUCAULT apud MAINGUENEAU, 2008, p.16). 
Ensino, Saúde e Ambiente - V9 (3), pp. 346-372, Dez. 2016

\section{Aspectos Éticos da Pesquisa}

Este trabalho obteve parecer favorável do Comitê de Ética em Pesquisa (CEP) do Hospital Naval Marcílio Dias, sob Parecer 024/2008, referente ao protocolo de pesquisa $\mathrm{n}^{\circ} 005 / 2008$, segundo as normas éticas vigentes no País para pesquisa envolvendo seres humanos (Resolução nº 196/96 do Conselho Nacional de Saúde, vigente à época).

O registro na Comissão Nacional de Ética em Pesquisa - CONEP possui cadastro de Folha de Rosto $\mathrm{n}^{\circ} 197189$ e CAAE $\mathrm{n}^{\mathrm{o}}$ 0006.0.221.000-08, que pode ser verificado no endereço eletrônico: < HTTP://portal.saude.gov.br/sisnep/cep/extrato_projeto.cfm>, página do Sistema Nacional de Informações Sobre Ética em Pesquisa envolvendo Seres Humanos SISNEP.

\section{DISCUSSÃO E ANÁLISE DOS RESULTADOS}

A partir do roteiro com perguntas semiestruturadas, foram realizadas cinco entrevistas com os sujeitos do estudo, Sargentos Enfermeiros egressos do Curso Expedito de Suporte Básico de Vida a Distância da Escola de Saúde do HNMD. Seguem-se as características de cada um:

Sujeito 1: graduação de Primeiro-Sargento e 19 anos de Marinha, casado, natural do Rio de Janeiro RJ, 15 anos de exercício profissional militar em enfermagem e com formação superior em Pedagogia;

Sujeito 2: graduação de Segundo-Sargento e 17 anos de Marinha, casado, natural de Salvador BA, 13 anos exercício profissional militar em enfermagem e com formação superior em Direito;

Sujeito 3: graduação de Terceiro-Sargento com 15 anos de Marinha, solteiro, natural do Rio de Janeiro RJ, com 11 anos de exercício profissional militar em enfermagem, com formação superior em Processamento de Dados e Direito;

Sujeito 4: graduação de Terceiro-Sargento com 13 anos de Marinha, casado, natural do Rio de Janeiro RJ, com 09 anos de exercício profissional militar em enfermagem, cursando Enfermagem de nível superior;

Sujeito 5: graduação de Terceiro-Sargento, também com 13 anos de Marinha, casado, natural de João Pessoa PB, com 09 anos de exercício profissional militar em enfermagem e cursando Enfermagem de nível superior. 


\section{Ensino, Saúde e Ambiente - V9 (3), pp. 346-372, Dez. 2016}

\section{CATEGORIAS PARA ANÁLISE DOS DISCURSOS}

\section{Interação instrutor-aluno na fase à distância do SBV}

Bem, na fase à distância eu senti uma relação muito fria. Mesmo sendo à distância, essa relação tem que ser mais próxima do aluno, porque pelo fato de ser à distância, a meu ver... tem que ser mais próxima para evitar que o aluno passe essa fase toda com muitas dúvidas. Com dúvidas vai passar, mas essa dúvida tem que ser a menor possível, em menor quantidade, isso pra mim só com um acompanhamento mais próximo entre um aluno e a instrutoria, tutoria, não sei o nome correto (pausa) por isso eu achei fria, um pouco distante entre eu e o curso em si... (pausa) a instrutoria do curso, só acho que isso foi melhor dirimido quando na ocorrência da fase presencial essa relação ficou melhor estabelecida ... sem dúvida, a parte presencial foi fantástica, tirou...(pausa) além das dúvidas, acrescentou... (pausa) mas ainda assim eu tive mais dificuldade na fase presencial por conta da grande separação da parte... da parte em que é à distância. $\left(\mathrm{S}_{1}\right)$

Foi muito boa, todos os meus questionamentos que eu tive, todas as minha dúvidas foram sanadas, o que eu não consegui obter na parte do material, eu consegui com os instrutores. $\left(\mathrm{S}_{2}\right)$

A princípio a gente sente um pouco de dificuldade, aquele que não tem uma facilidade que é o meu caso com o meio digital a gente tem uma visão um pouco afastada que o instrutor se faz afastado de você. Pela quantidade de cursos que eu tenho que normalmente a gente ver o instrutor sempre todo o momento, então quando a gente tem um instrutor que ele está numa longa distância a gente num primeiro momento fica um pouco assustado, mas pela perícia técnica do instrutor que está querendo buscar o aluno pra a questão virtual, a questão do ensino no decorrer da matéria a gente se sente mais integrado. $\left(\mathrm{S}_{3}\right)$

Excelente, muito bom. Principalmente por que pra tirar as dúvidas era só seguir o horário do fórum, não é?,tinha que ter o acesso e dentro do acesso a gente respondia conforme as instruções. Não tive problema algum. $\left(\mathrm{S}_{4}\right)$

- Eu acho que há momentos que você consegue até ter um acesso mais fácil até pela questão do instrutor não estar o tempo todo conectado à Internet, mas posso considerar como razoável. $\left(\mathrm{S}_{5}\right)$ 
As falas remetem à dificuldade inerente à $\mathrm{EaD}$ : falta do estabelecimento da relação professor-aluno na fase à distância, que pode ser evidenciada nos recortes da fala do Sujeito 1. O entrevistado expressa ainda a dificuldade quando não sabe o termo correto para se referir àquele que se constitui no lugar de quem ensinou (instrutor ...tutor). O termo é tutor, mas a palavra 'instrutor' remete à idéia de instruir, de passar conhecimento ao outro, numa perspectiva conteudista do processo ensinoaprendizagem. Essa é uma concepção de aprendizagem tecnicista. O tutor pode ser aquele que se constitui como mediador, como alguém que dá significado ao que o outro - aluno está em vias de aprender. Essa linha de raciocínio confirma-se no que está explicitado a seguir:

O processo de formação de conceitos (...) é longo e complexo (...) conceito não é aprendido por meio de um treinamento mecânico, nem tampouco pode ser meramente transmitido pelo professor ao aluno: "o ensino direto de conceitos é impossível e infrutífero. Um professor que tenta fazer isso geralmente não obtém qualquer resultado, exceto o verbalismo vazio. (VYGOTSKY, 1987, p.72)

O papel do tutor é o de intermediar as relações de aprendizagem, de ser o facilitador da construção desse conhecimento valendo-se das contribuições individuais acerca dos temas discutidos, pois, segundo Rego (2000, p. 78-79), “o pensamento conceitual é uma conquista que depende não somente do esforço individual mas, principalmente, do contexto em que o indivíduo se insere.

Apesar de existirem sujeitos que afirmam a eficiência dessa fase, existe sempre a referência ao tutor também como instrutor, o que leva à afirmação da análise feita acima. A dificuldade da distância do tutor aparece ainda na fala do Sujeito 3, que usa a expressão "a gente", um índice de análise do discurso que traz a voz de outra pessoa junto à sua, procurando dar estatuto de verdade à própria fala.

Essa análise ajudará, mais adiante, a modificar a parte à distância do curso analisado, haja vista que a relação ensino-aprendizagem baseada na idéia do mediador precisa ser desenvolvida. A visão do professor/instrutor/tutor/mediador deve ser trabalhada sim, mas percebe-se que a maior dificuldade na fase à distância é a falta da sistematização da sala de aula militar, em que disciplina e a hierarquia são fatores presentes no processo ensino-aprendizagem, ainda que com professores civis. No processo ensino-aprendizagem à distância, o aluno se "despe da farda" e o professor também, e ambos tem que se fazer parceiros no processo, mas com sua autonomia 


\section{Ensino, Saúde e Ambiente - V9 (3), pp. 346-372, Dez. 2016}

intelectual preservada. Isto pode ser confirmado/embasado pelo grande percentual de maior solicitação de tempo na fase presencial.

Durante toda fase à distância, o aluno tem disponíveis ferramentas de interação, onde são discutidas temáticas junto ao tutor, em tempo real previamente agendado, quando são determinadas atividades em grupo a serem desenvolvidas pelos alunos em seus locais de acesso e, posteriormente, apresentadas como atividade de grupo na fase presencial, ocasião em que as dúvidas sobre os conteúdos são esclarecidas pelo tutor.

\section{Relação máquina vs tutor $v s$ aprendente ${ }^{6}$}

Não, não vejo dificuldade alguma, desde que tutor esteja mais próximo do aluno mesmo que virtualmente, mas não vejo problema quanto a isso não. (S1)

Olha... sempre há alguma dúvida que fica, alguma coisa que você não acha logo de primeira, mas isso daí no decorrer do curso você vai sanando, você se adequando a linguagem que é utilizada pelo Sistema. Logo de princípio no meu caso..., como eu nunca tinha feito nenhum curso de ensino à distância, eu senti que tinha algumas coisas que eu teria que dar mais ênfase, mas logo depois foi muito fácil. (S2)

Não. Eu não vejo dificuldade, embora a máquina hoje em dia, ela facilita a digitação, aquela coisa toda, eu acho que fica bem interessante. Se tivesse uma ferramenta de webcam que a gente está vendo o instrutor seria muito interessante. (S3)

Há dificuldade se não houver uma dessas partes ...tirou uma dessas partes aí, eu acho que há dificuldades. Lembrando que se não houver apoio logístico da própria Organização Militar em que o militar se encontra, se não houver então vai ser mais uma dificuldade. (S4)

- Não, não tive dificuldade de lidar com ferramenta não, talvez porque os computadores estão muito presentes hoje em dia, não é um instrumento distante da realidade atual. (S5)

\footnotetext{
${ }^{6}$ Aprendente/Ensinante: O emprego dos termos aprendente-ensinante usados por Fernández [3],abre um espaço para pensar o conceito de sujeito em psicopedagogia,isto é,sujeito de autoria de pensamento.. Conceituar a relação aprendente-ensinante nos permite dirigir nosso olhar, com muita abrangência e profundidade em questões nodais, referentes à singularidade e o modo subjetivo de situar-nos em relação com o conhecimento. Podemos mesmo dizer que são vitais para sobreviver, crescer e construir nossa inteligência, bem como as nossas modalidades de pensar. disponível em: http://www.pp.ufu.br/Cobenge2001/trabalhos/APP041.pdf
} 
Mesmo tendo que lidar com questionamentos sobre o uso do computador como espaço de aprendizagem, os entrevistados ainda ressaltaram papel do professor como, por exemplo, na fala do Sujeito 1 , que relatou o que foi dito acima quanto à presença do tutor na $\mathrm{EaD}$; ou seja, o professor não precisa estar necessariamente presente no mesmo espaço daquele que aprende, mas deve haver a possibilidade de construção de um diálogo.

Além disso, a idéia de que a aprendizagem se dá pela única ação daquele que aprende apareceu novamente trazendo, mais uma vez, uma abordagem inatista da construção do conhecimento:

Olha... sempre há alguma dúvida que fica, alguma coisa que você não acha logo de primeira, mas isso daí no decorrer do curso você vai sanando, você se adequando a linguagem que é utilizada pelo Sistema. Logo de princípio no meu caso..., como eu nunca tinha feito nenhum curso de ensino a distância eu senti que tinha algumas coisas que eu teria que dar mais ênfase, mas logo depois foi muito fácil. (S2)

\section{Contribuições para a vida profissional geradas pelo curso SBV à distância}

Diretamente nenhuma [contribuição], porque eu não exerço a função de enfermeiro, mas para aquele que exerce é sobremaneira excelente, fantástico, importantíssimo, eu acho que afeta diretamente a vida. Ele, o enfermeiro comum, comum que eu digo é o que não tem essa visão do SBV, ele passa a não ser mais comum. (S1)

Indagado acerca do grau de importância que esse curso teria em sua vida profissional, do ponto de vista militar inserido num contexto como enfermeiro, atuando em uma área operativa dentro de um navio, ele respondeu:

Numa escala de 0 a 5, seria 6. É assim, tanto o ESP quanto a AP, ambos possuem a disciplina de emergência pelo menos na minha época não supria de forma alguma o $S B V$, que por si só eu vejo como uma subespecialidade de tamanha importância no curso que eu vi ao fazê-lo é...(pausa), o Cabo, o Sargento recém formado não tem como agir principalmente na parte operativa. Vamos botar no caso da Gola ${ }^{7}$ no navio, não tem como agir no caso de guerra, ou até mesmo em tempo de paz, mas enfim, em caso

\footnotetext{
${ }^{7}$ Da "Gola" são os militares do Corpo da Armada da Marinha do Brasil. É um Corpo também composto por Praças que são admitidos por concurso, cursam Escola de Aprendiz, iniciam a carreira como Marinheiros fazem sua opção profissional e se Especializam nas diversas áreas disponibilizadas na Força Militar.
} 
Ensino, Saúde e Ambiente - V9 (3), pp. 346-372, Dez. 2016

em que seja necessário agir dessa forma com o suporte básico de vida, o paciente no caso, ferido, vai sofrer muito para ser salvo, diferentemente de um enfermeiro que possua o SBV, que saberá agir de maneira muito mais direta e efetiva sobre a ocorrência. (S1)

O Sujeito 2 respondeu o seguinte:

Contribui para o aprendizado, é adicionar ao meu conhecimento técnico que eu já tinha com relação ao suporte básico de vida, foi um "quê" a mais, foi uma nova esfera que eu pude visualizar também.(S2)

Quando perguntado sobre sua vida profissional e o período em que passou embarcado, com a maturidade profissional que possui, e se considerava que as contribuições do curso de suporte básico de vida à distância fariam com que se sentisse mais seguro para atuar numa situação de embarque imediato, sabendo que nem sempre tem um médico presente e que o enfermeiro pode estar diante de uma situação de risco de vida, de grave ocorrência, o mesmo entrevistado respondeu prontamente:

Poxa, isso eu posso dizer, porque já estive dos dois lados. Já trabalhei numa fase em que eu tinha acabado de sair do ESP e fui trabalhar num local onde pegava-se muitos pacientes graves e não tinha conhecimento. Eu posso dizer de carteirinha que com o suporte básico de vida, a visão é completamente diferente... para quem está cego, é uma luz no fim do túnel. (S2)

O Sujeito 3 pronunciou-se também sobre o assunto que estava sendo abordado:

Como eu falei anteriormente, eu passei por vários cursos e em cada curso tínhamos uma tendência a adaptar o que o instrutor sempre nos trazia. Com relação à enfermagem em si, o conteúdo à distância, ele veio somar a parte técnica da enfermagem, eu não via mais a questão de primeiros socorros num suporte básico de vida como militar em área de conflito, eu via como um profissional de saúde que tinha que ter um conhecimento mais apurado para poder satisfazer a minha vítima, fazer um atendimento à minha vítima com maior eficácia, então, o curso propicia tal momento como profissional de saúde. (S3)

Ao ser indagado sobre manobras e missões, embarque em navios e manobras em áreas e/ou condições inóspitas, se pudesse fazer hoje um comparativo entre as manobras 
que fez em todas essas condições difíceis, antes e após a realização do curso, referiu-se às contribuições que o aprendizado havia oferecido em relação ao seu desempenho profissional, ele respondeu:

Ele abriu um horizonte e da mesma forma que ele abriu um horizonte no tocante a Especialidade, ele me deu ma outra visão operacional. Um exemplo que vejo hoje uma necessidade maior de carregar um pouco mais de peso. Então o que a gente fazia tradicionalmente que era carregar um bornal que continha determinadas coisas, hoje em dia eu vejo que preciso carregar algo mais, pois é algo mais que vai fazer a diferença pra minha vítima até chegar no intra-hospitalar. Enfim, o contato com a minha vítima agora, neste momento se houver alguma... espero que não..., mas se tiver estarei pronto para tal, vai ser diferente, por que eu vou tratar essa vítima preparando ela pra chegar no intra hospitalar. Eu não vou prepará-la apenas para continuar a missão. Eu vou prepará-la pra ela chegar no intra hospitalar sem seqüela nenhuma.

O Sujeito 4 referiu-se à realização do curso à distância, considerada uma experiência válida, conforme explicou:

Primeiro é entender como é que funciona um curso na área de saúde a distância que alguns acham que é de baixo nível, digo na graduação, se você colocar nota, eu diria que é do mesmo nível dos cursos presenciais, mas para mim, me atualizou até para entender como funciona a parte virtual. (S4)

Acerca de questões relacionadas ao embarque, questionado se os conhecimentos do curso contribuiriam para melhorar a atuação profissional neste contexto, ele respondeu:

Contribuiriam muito (...) depois disso não dá mais para voltar atrás; para quem não tem acesso, não tem tempo para vir e cursar da forma exclusivamente presencial, cairia como uma luva, e até para algumas OM que não tenham condições de suportar outros cursos que não sejam de Marinha, esse curso já atinge pessoas em lugares que a gente nem imagina. (S4)

O Sujeito 5 destacou a importância do curso à distância para os profissionais de enfermagem em geral:

Quando se tem a formação de enfermagem aqui na Escola de Saúde, a gente tem uma formação assistencial, que fica um pouco distanciado da questão do pré-hospitalar, aí 
quando você vem e faz um curso como o de suporte básico de vida e começa a criar um caminho sobre a questão do pré-hospitalar e é passada a importância desse primeiro atendimento prestado à vítima, você manter ali a viabilidade dos órgãos nobres até um suporte avançado é fundamental, eu acho que todo técnico ou auxiliar de enfermagem deveria ter acesso a esse tipo de informação. (S5)

Quando foi indagado se considerava que haveria mais facilidade de ação assistencial após o curso, caso estivesse embarcado cumprindo alguma missão, sendo ele o enfermeiro de bordo, respondeu:

Com certeza facilitaria ... como havia falado, aqui a gente tem na Escola de Saúde uma formação para o assistencial e o curso de SBV, ele vem abrindo os caminhos para o atendimento pré-hospitalar, que vai permitir que se faça um atendimento a essa vítima, mantendo uma viabilidade melhor, porque os conhecimentos são passados até a chegada do suporte avançado, ou seja, prepara melhor o enfermeiro para estar atuando isoladamente, num caso de estar embarcado. (S5)

Destaque deve ser dado à fala do Sujeito 4, escolhida por ser emblemática no que tange às discussões atuais quando se trata da $\mathrm{EaD}$ diante da educação regular, presencial, pois ele identifica o mesmo nível e, logo em seguida, indaga qual seria a finalidade da $\mathrm{EaD}$. A resposta para o questionamento é que a $\mathrm{EaD}$ surgiu com a perspectiva de possibilitar acesso ao conhecimento àqueles que não estão em locais possíveis para a realização da educação presencial. Essa é a finalidade do curso analisado.

Verificou-se, portanto, que a obtenção de conhecimentos em situações de emergência em suporte básico de vida será facilitada a partir de possibilidades educativas disponibilizadas por meio de recursos tecnológicos, como a rede mundial de computadores, que podem facilitar o aprendizado de militares que se encontrem distantes de pólos educacionais presenciais para o aprendizado de manobras de salvamento, conforme protocolos de atendimento preconizados internacionalmente.

\section{CONCLUSÃO}

Considerando as dificuldades encontradas em virtude da idéia de estudar um tema novo, frente às tradições encontradas em sala de aula presencial no exercício da minha atividade na Escola de Saúde enquanto instrutor militar, permitiu a constatação de que a atividade de ensino virtual é válida a partir do instante em que o aluno está disposto a desvendar novos conhecimentos para o aprimoramento da sua atividade profissional e, principalmente, pelo compromisso em salvar vidas. 
O compromisso, a seriedade e a responsabilidade da atuação do enfermeiro, civil (de nível superior) ou militar (de nível médio), ou superior exige que a busca pelo conhecimento profissional, em suas diversas especialidades, seja incansável.

O impacto causado pela implantação do curso de Suporte Básico de Vida à Distância foi percebido pela grande procura identificada quando da divulgação, em meios de comunicação interna da Marinha do Brasil, a abertura de novas turmas.

As ferramentas disponibilizadas no ambiente virtual de aprendizagem facilitaram os processos de interação das salas de aula virtual, fato observado quando algumas vezes, despretensiosamente, durante as madrugadas, identificamos grupos de aprendentes em salas de bate-papo "teclando" sobre as temáticas do curso e a apresentação de atividades na fase presencial.

O Curso "Suporte Básico de Vida a Distância", via web, é o único entre as Forças Armadas e Auxiliares nesta modalidade, atendendo não só aos militares da localidade, como também àqueles embarcados em hospitais distritais.

Os resultados da pesquisa de campo baseado nas entrevistas remonta à importância do curso e à oportunidade de adquirir novos conhecimentos por computador sabendo que, de fato, se trate de uma sala de aula virtual, há alguém "do outro lado" interagindo, permitindo que o aprendente não esteja solitário. Porém, dificuldades foram encontradas para sensibilizar os Comandos Militares de que, uma vez matriculado, o militar necessita cumprir as atividades do curso cujas regras, mesmo à distância, precisam ser cumpridas sob pena de uma reprovação que poderá comprometer sua carreira militar. Tais dificuldades estavam relacionadas às obrigações com as atividades diárias à distância, visto que o militar não é destacado de sua $\mathrm{OM}$ para cursar como tradicionalmente ocorre no ensino presencial, exceto para cumprimento de etapa correspondente e, a sua rotina laboral por vezes não pode ser comprometida em função da necessidade de um curso à distância.

Dentro dos navios os riscos de ocorrência de sinistros são possíveis. Sendo assim, como proceder se o militar não tiver preparo técnico suficiente para interceder frente à situações limítrofes, considerando que será necessário utilizar meios para suporte à vida, com manejos adequados para locomoção onde haja recursos avançados de procedimentos?

A partir dessas evidências, a proposta de criação do curso e sua real aplicabilidade veio propiciar aos militares que atuam na assistência à saúde, a oportunidade de adquirir conhecimentos necessários, indispensáveis mesmo, frente às 
novas possibilidades de educação, para sanar as dificuldades de execução de padrões internacionais de qualidade em situações de primeiro atendimento às vítimas de sinistros nos respectivos âmbitos de trabalho na Marinha do Brasil.

O Curso de Suporte Básico de Vida à Distância, desde sua implantação em 2006 até os dias atuais, devido à grande procura por militares e Comandos das OM, tem sido utilizado com a preocupação de manter profissionais preparados para atuação em situações de emergência em saúde.

Diante do exposto, considera-se comprovada a relevância do estudo, e ainda, que os seus objetivos foram alcançados, inclusive com reflexos positivos junto à Diretoria de Ensino da Marinha (DEnsM) ao reconhecer a importância para o aprendizado de nossos militares, e à Diretoria de Saúde da Marinha (DSM), que busca qualificar seus militares para uma atuação com resultados eficazes, estimulando a criação de outros cursos na mesma modalidade.

\section{REFERÊNCIAS}

ALCANTARA, Leila Milman. A Enfermagem militar operativa: gerenciando o cuidado em situações de guerra.288p. RJ,Julho,2005.Tese de doutorado em Enfermagem,UFRJEscola de Enfermagem Anna Nery.

CHARAUDEAU, Patrick; MAINGUENEAU, Dominique; coordenação da tradução Fabiana Komesu. Dicionário de análise do discurso. 2.ed., $2^{\mathrm{a}}$ reimpressão. - São Paulo: Contexto, 2008.

CASTRO G.L.T. Atendimento pré-hospitalar móvel: mapeando riscos e prevenindo erros. Dissertação (mestrado) - Universidade Federal do Rio Grando do Norte (UFRN), Centro de Ciências da Saúde, Departamento de Enfermagem, 2013. Disponível em: https://repositorio.ufrn.br/jspui/bitstream/123456789/14783/1/GrayceLTCDISSERT.pdf Acesso em 22/10/2016

Comitê do PHTLS da National Association of Emergency Medical Technicians (NAEMT) em colaboração com o Colégio Americano de Cirurgiões. Atendimento préhospitalarao traumatizado: básico e avançado. Rio de Janeiro: Elsevier, 2007

DEnsM-5001. Manual para elaboração de cursos a distância, da Diretoria de Ensino da Marinha, Ostensivo - Marinha do Brasil; 2005. 86 p.

DINIZ, R.; SILVA, D.B. da, Primeiros socorros no esporte. Coleção Pesquisa em Educação Física, Várzea Paulista, v. 14, n. 04, p. 149-156, 2015. ISSN 1981-4313

FONSECA K. Primeiros Socorros. Disponível em http://www.brasilescola.com/saude/primeiros-socorros. htm. Acesso em: 22/02/2015. 
LÉVY P. As tecnologias da inteligência. O futuro do pensamento na era da informática. Rio de Janeiro:

Editora 34; 1993.

LÜDKE, Menga. Pesquisa em Educação: abordagens qualitativas. São Paulo: EPU, 1986.

MAINGUENEAU, Dominique; tradução Sírio Possenti. Gênese dos discursos. São Paulo: Parábola Editorial, 2008

MINAYO, M. C. S. O desafio do conhecimento: pesquisa qualitativa em saúde. São Paulo: Hucitec/Abrasco, 2008.

MARINHA DO BRASIL. Hospital Naval Marcílio Dias 70 anos. Rio de Janeiro: MCE; 2004.

MARTINS, H. T. S. Metodologia qualitativa da pesquisa. Educação e Pesquisa, São Paulo, v. 30, p. 287-298, maio/ago. 2002.

MORAN, José Manuel. A Educação que desejamos: novos desafios e como chegar lá. Campinas (SP): Papirus, 2007.

NUNES, I. B. A história da EAD no mundo. In: LITTO, F. M.; FORMIGA, M. M. M. (Org.). Educação a distância: o estado da arte. São Paulo: Pearson Education do Brasil, 2008.

OLIVEIRA, Luiza Rodrigues. Sujeito como interface entre a escola que reproduz e que transforma.SP,2003.Tese de doutorado em educação, Universidade de São Paulo, USP,Brasil

PERGOLE, A.M.; ARAUJO, I.E.M. O leigo e o Suporte básico de Vida. Rev.Escola de Enfermagem da USP. V.43, n.2, p. 335-4, 2008.

PETERS, Otto. Didática do ensino a distância. São Leopoldo: Editora Unisinos, [s.d.].

ROCHA, M.P.S ; Protocolo de avaliações Suporte Básico de Vida e Socorros de Emergência - AVM Instituto. Brasília - DF 2011. Unidade I cap. 1 Atendimento pré$\begin{array}{llllll}\text { hospitalar e Avaliação Inicial da Vítima } & - & \text { p9 }\end{array}$ $\langle$ http://1ms.ead1.com.br/webfolio/Mod5986/mod_suporte_basico_v5.pdf $>$ acesso em $05 / 12 / 2016$

TORRES; FIALHO In: Litto FM, Formiga MMM. Educação a Distância: o estado da arte. São Paulo: Pearson Education do Brasil; 2009

A prática reflexiva no ofício professor: profissionalização e razão pedagógica. Porto Alegre: Artmed, 2002.

REGO, Teresa Cristina. Vygotsky: uma perspectiva histórico-cultural da Educação. 10. ed. Petrópolis: Vozes, 2000. 
Ensino, Saúde e Ambiente - V9 (3), pp. 346-372, Dez. 2016

SANCHO, J. M.; HERNÁNDEZ, F. Tecnologias para transformar a educação. Porto Alegre: Artmed, 2006.

SANTOS, Izequias Estevam dos. Manual de métodos e técnicas de pesquisa científica. 5.ed.rev., atual. e ampl. - Niterói, RJ: Impetus, 2005

A inteligência coletiva: por uma antropologia do ciberespaço. São Paulo: Edições Loyola, 1998.

2000.

Cibercultura. Tradução: Carlos Irineu da Costa. 2. ed. São Paulo: Editora 34,

O trabalho docente: elementos para uma teoria da docência como profissão de interações humanas. Tradução de João Batista Kreuch. Petrópolis: Vozes, 2005.

www.sdm.mar.mil.br

www.mar.mil.br

www.mar.mil.br/cgcfn 